\title{
Correction to: medical students can teach communication skills - a mixed methods study of cross-year peer tutoring
}

Osamu Nomura ${ }^{1,2^{*}}$, Hirotaka Onishi ${ }^{3}$ and Hiroyuki Kato ${ }^{1}$

\section{Correction}

Following publication of the original article [1], the authors reported that the word "Tutee" on the righthand side of Fig. 3 should read "Tutor".

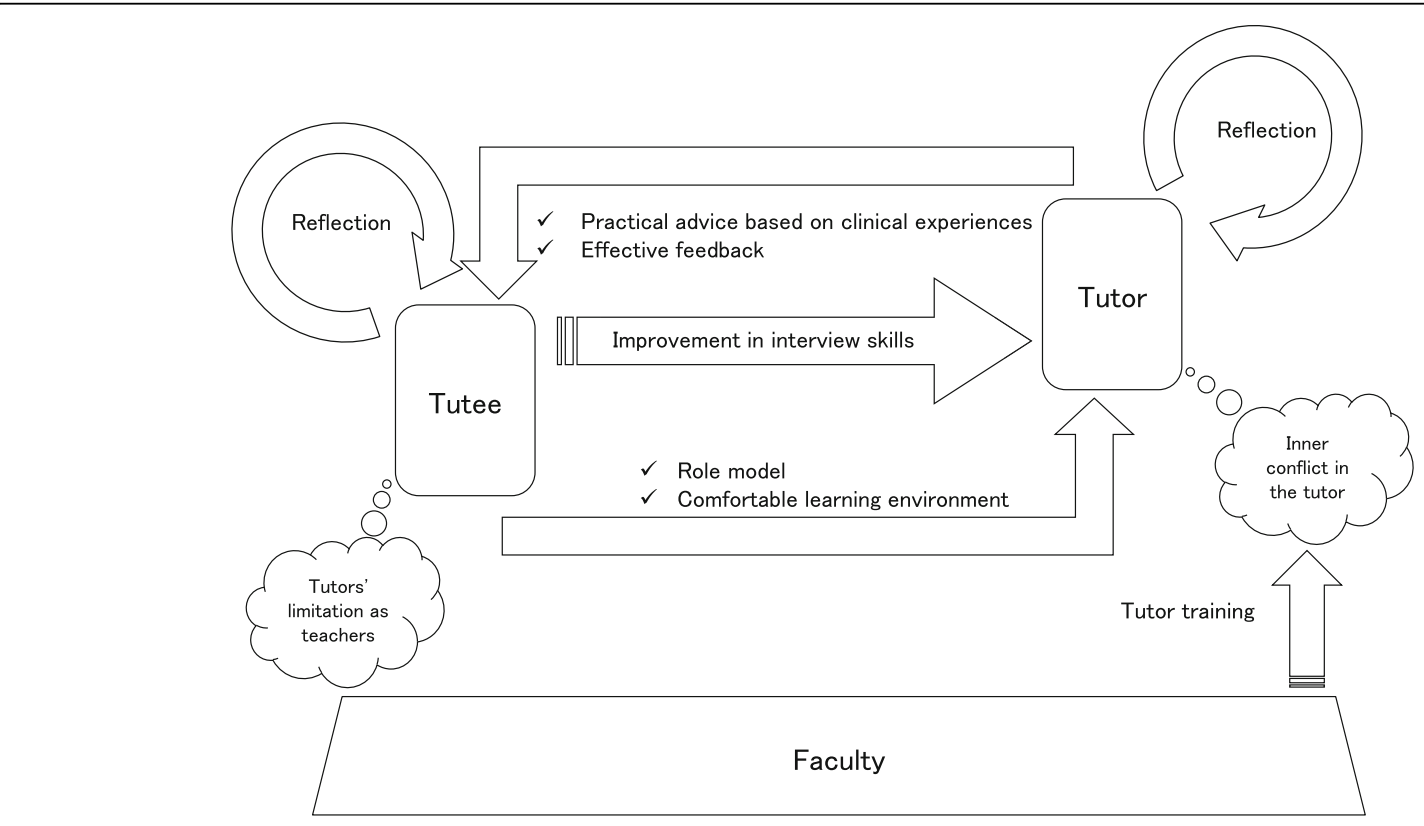

Fig. 3

\section{Author details}

'Department of Integrated Medical Education, Graduate School of Medicine, Hirosaki University, 1 Zaifu-cho, Hirosaki city, Aomori, Japan. ${ }^{2}$ Division of Pediatric Emergency Medicine, Tokyo Metropolitan Children's Hospital, 2-8-29 Musashidai, Fuchu city, Tokyo, Japan. ${ }^{3}$ International Research Center for Medical Education, Graduate School of Medicine, The University of Tokyo, 7-3-1 Hongo, Bunkyo-ku, Tokyo, Japan.
Received: 18 September 2017 Accepted: 18 September 2017 Published online: 20 October 2017

\section{Reference}

1. Nomura O, Onishi $\mathrm{H}$, Kato H. Medical students can teach communication skills - a mixed methods study of cross-year peer tutoring. BMC Med Educ. 2017;17:103. DOl:10.1186/s12909-017-0939-7.

\footnotetext{
* Correspondence: osamunomura@hotmail.com

${ }^{1}$ Department of Integrated Medical Education, Graduate School of Medicine, Hirosaki University, 1 Zaifu-cho, Hirosaki city, Aomori, Japan

${ }^{2}$ Division of Pediatric Emergency Medicine, Tokyo Metropolitan Children's

Hospital, 2-8-29 Musashidai, Fuchu city, Tokyo, Japan
} 